\title{
Bisphosphonate-related osteonecrosis of the jaws: A report on 30 cases
}

\author{
Mario Migliario ${ }^{1}$, Andrea Melle ${ }^{1}$, Vittorio Fusco ${ }^{2}$, Lia Rimondini ${ }^{1}$ \\ ${ }^{1}$ Department of Health Sciences, Università del Piemonte Orientale "Amedeo Avogadro", Alessandria, Novara, Vercelli, Italy \\ ${ }^{2}$ Medical Oncology Unit, Department of Oncology and Hematology, Ospedale SS Antonio e Biagio e C. Arrigo, Alessandria, Italy \\ Email: mario.migliario@med.unipmn.it, mario.migliario@,virgilio.it
}

Received 1 May 2013; revised 2 June 2013; accepted 29 June 2013

Copyright (C) 2013 Mario Migliario et al. This is an open access article distributed under the Creative Commons Attribution License, which permits unrestricted use, distribution, and reproduction in any medium, provided the original work is properly cited.

\begin{abstract}
Aim: To report a series of thirty cases of bisphosphonate-related osteonecrosis of the jaw (BRONJ). Material and Methods: For 30 patients with BRONJ, gender, age, underlying diagnosis, type of bisphosphonate (BP), administration route and duration, location and stage of osteonecrosis, symptoms and oral health status, radiological findings of the jaws, treatment and outcome, were recorded. Results: Underlying diagnoses in the series (12 male; 18 female; mean age $70.50 \pm 9.62)$ were: 12 multiple myeloma, 7 breast cancer, 3 prostate carcinoma, 1 kidney/lung/ bladder/mediastinal cancer, 1 chronic lymphocytic leukemia, 1 osteoporosis, 1 palatal osteosarcoma + osteoporosis, 1 non-Hodgkin's lymphoma. Forty-seven osteonecrotic lesions were detected; 30 localized in the mandible, 17 in the maxilla; trigger events were tooth extraction in 31 cases $(66 \%)$, periodontal disease in $4(8.50 \%)$, incongruous dentures in $3(6.40 \%)$, perimplantitis in $1(2.10 \%)$, unknown in $8(17 \%)$. Twenty-nine patients had received treatment using amino bisphosphonates (25 zoledronate, 2 pamidronate, 2 alendronate) and 1 clodronate; the administration route was intravenous in 27 patients, oral in 2 and intramuscular in 1. Mean number of doses to bone exposure for patients was $\mathbf{3 4 . 1 1}$ for zoledronate, $\mathbf{5 0 . 5 0}$ for pamidronate, 146 for alendronate, and 500 for clodronate. Among statistical data the only significant finding was that panoramic dental radiography gave no concrete support for diagnosis of ONJ lesions $(p \leq 0.04)$. Conclusions: Our case series reflects literature data. We emphasize the insufficient role of panoramic radiography to study osteonecrotic lesions and the role of poor oral hygiene.
\end{abstract}

Keywords: Bisphosphonates; Jaws; Osteonecrosis; Panoramic Radiograph; Dental Hygiene

\section{INTRODUCTION}

Bisphosphonates (BPs) are a class of drugs derived from pyrophosphates, endogenous inorganic regulators of mineralization, by substituting the oxygen atom in the basic pyrophosphate chain with a carbon; this leads to osteoclast inhibition, decreasing bone resorption [1-3]. Different generations of BPs have been created, with distinct pharmacological potency [1-3]. The first generation of BPs comprises etidronate and clodronate, characterized by a chlorine atom. The second generation of BPs comprises alendronate and pamidronate, in which an amino-terminal group has been introduced; these drugs have antiresorptive potency that is 10 - 100 times higher than that of etidronate and clodronate. Zoledronate is a $\mathrm{BP}$ of the third generation, and has an imidazole ring group in the side chain with the potency about 100 times higher than pamidronate. The administration route for clodronate is intramuscular or oral or intravenous, for alendronate it is oral, and for pamidronate and zoledronate it is only intravenous [1-3]. The effects of BPs include the reduction of bone loss and of the risk of pathological fractures; these drugs are thus administered to patients suffering from destructive bone lesions resulting from osteoclast-induced resorption [3-5]; they are mainly used to treat and prevent malignant hypercalcemia, skeletal-related events associated with bone metastases secondary to solid cancer, and in the management of the lesions of multiple myeloma, Paget's disease, primary and secondary hyperparathyroidism and osteoporosis [2-11]. Starting from 2003, reports began to appear of necrotic bone exposure of the jaw $[12,13]$ in patients receiving BPs for multiple myeloma and bone cancer metastases: the osteonecrotic lesions are now known as bisphosphonate-related osteonecrosis of the jaw (BRONJ) $[14,15]$. This phenomenon has mainly been observed after intravenous administration of BPs containing nitrogen $[9,12,14-26]$. Following the early reports, several 
other cases of BRONJ have also been reported in osteoporosis patients treated with BPs [27-32]. This study reports on 30 patients with jaw exposure who had undergone treatment with BPs.

\section{MATERIAL AND METHODS}

\subsection{Sample}

The study received permission from the local ethics committee (EC study protocol 61/10) and was carried out in accordance with the ethical standards of the Helsinki Declaration of 1964 . Thirty patients with jaw bone exposure of at least 8 weeks duration, with no history of head and neck radiation therapy, history positive for BPs therapy and negative for local radiation therapy, who had been referred to our Department between May 2005 and December 2011 were enrolled. After being informed of the aims and methods of the study, patients gave their written consent to participation. Sex, age, underlying diagnosis, type, duration, and administration route of BP treatment, time of onset of ONJ, treatment and outcome were recorded for all patients. The disease stage was registered according to AAOMS staging system $[14,15]$. Oral examination determined oral health status, indexes of oral hygiene (GI, gingival index as per Löe and Silness; PI, plaque index, as per Silness and Löe) [33,34], location, size, and clinical symptoms of osteonecrosis. Data from instrumental analysis was also recorded.

\subsection{Statistical Analysis}

Statistical analysis was performed using SPSS (SPSS Inc. Chicago, US) for Windows, version 12, with $\mathrm{p}<0.05$ considered significant.

\section{RESULTS}

Having given their written informed consent, all patients were examined; no side effects were observed during the examinations. A total of 47 osteonecrotic lesions were detected in 30 patients $(12 \mathrm{~m} ; 18 \mathrm{f})$, fourteen afflicted by metastases of solid carcinomas ( 7 breast cancer, 3 prostate cancer and one respectively bladder, lung, kidney, mediastinal cancer), twelve by multiple myeloma, and one respectively by osteoporosis and palate osteosarcoma, chronic lymphocytic leukemia, non-Hodgkin lymphoma, osteoporosis. Onset of BRONJ was earlier in women (mean age 66.55 years old, min 43.25) than in men (mean age 68.12 years old, min 51.66) (Table 1). BRONJ occurred in 29 patients $(96.60 \%)$ who had been treated with aminoBPs (zoledronate, pamidronate, alendronate). Zoledronate alone (4 mg IV every 4 weeks) was administered to 21 patients ( $70 \%$ of the series); 4 patients $(13.40 \%)$ switched from pamidronate to zoledronate; other 2 patients $(6.70 \%)$ received pamidronate (90 mg IV every 4 weeks): one $(3.35 \%)$ pamidronate alone and one $(3.35 \%)$ switched from zoledronate to pamidronate; further 2 patients $(6.70 \%)$ took alendronate (70 mg OS weekly). Only one patient (3.30\%) with osteoporosis took a bisphosphonate containing chlorine (100 mg IM weekly) (Table 2). The onset of BRONJ was earlier in patients receiving zoledronate, alone or following pamidronate. The mean number of doses, administered IV, for patients affected by metastases of solid cancers, multiple myeloma, or osteoporosis + osteosarcoma, was 34.11 doses $(\min 8, \max 61, \mathrm{SD}+12.15)$ in the case of zoledronate and 50.50 doses (minimum 37, maximum $64, \mathrm{SD} \pm 19.09$ ) in the case of pamidronate. The single patient with chronic lymphocytic leukemia, and the one with non-Hodgkin's lymphoma, respectively took 32 and approximately 260 oral doses of alendronate. The mean time to onset of ONJ was 146 weeks. However, patients also took high doses of corticosteroids to treat leukemia and lymphoma. Only one patient $(3.30 \%)$ with osteoporosis took a bisphosphonate containing chlorine intramuscularly, approximately 500 doses (about 10 years) (Table 2). Oral examination showed that 5 patients were totally edentulous (4 women and 1 man), all wearing with removable dentures; in the 25 dentate patients oral health status and oral hygiene were poor: the mean value of the plaque index (PI) was 2.00 and this one of gingival index (GI) was 1.85 (Table 3). Of the 47 osteonecrotic lesions, $17(36.15 \%)$ were in the maxilla (8 right; 9 left) and $30(63.85 \%)$ in the mandible (13 right; 17 left). Sixteen patients had lesions in the mandible alone, 9 in the maxilla alone, and 5 had lesions in both jaws; this confirms reports in the literature indicating a higher percentage of BRONJ in the mandible. The stages of the lesions are reported in Table 4 and the trigger events are given in Table 5. Of our series, 23 patients (76.65\%) reported symptoms, while $7(23.35 \%)$ were completely asymptomatic at the time of observation. Twenty-one patients (70\%) reported pain; $19(63.30 \%)$ had signs of inflammation of the tissues surrounding the lesion; $13(43.30 \%)$ showed swelling of the tissues surrounding the exposed bone; $13(43.30 \%)$ reported difficulty in mastication; $3(10 \%)$ had a cutaneous fistula; 2 $(6.70 \%)$ an oromaxillary fistula; $1(3.30 \%)$ had a mandibular fracture. The signs of BRONJ mentioned in the radiologists" reports are "structural alteration of trabecular bone, osteolytic lesion, cortical bone erosion, areas of bone destruction, osteosclerosis, radiolucent lesion corresponding to empty socket, small or extensive radiopaque sequestra, presence of periosteal reaction, mucoperiosteal thickening in the maxillary sinuses, oroantral communication" [26,35-38]. All patients $(\mathrm{N}=30)$ at the time of the examination had a recent panoramic radiograph (OPT), but in only $8(26.70 \%)$ cases signs of possible osteonecrosis have reported by radiologists; thirteen patients $(43.30 \%)$ had a Computerized Axial 
Table 1. Patients characteristics. BPs: Bisphosphonates; MM patients: patients affected by multiple myeloma; MTS: metastases of solid cancer.

\begin{tabular}{|c|c|c|}
\hline \multirow{7}{*}{ Gender } & Male & $12(40.0 \%)$ \\
\hline & Female & $18(60.0 \%)$ \\
\hline & Multiple Mieloma & $12(40 \%)$ \\
\hline & Chronic lymphocytic leukemia & $1(3.33 \%)$ \\
\hline & Non-Hodgkin's lymphoma & $1(3.33 \%)$ \\
\hline & Breast cancer & $7(23.3 \%)$ \\
\hline & Prostate cancer & $3(10 \%)$ \\
\hline \multirow[t]{13}{*}{ Primary disease } & Bladder cancer & $1(3.33 \%)$ \\
\hline & Lung cancer & $1(3.33 \%)$ \\
\hline & Kidney cancer & $1(3.33 \%)$ \\
\hline & Mediastinal cancer & $1(3.33 \%)$ \\
\hline & Osteoporosis & $1(3.33 \%)$ \\
\hline & Palate osteosarcoma + Osteoporosis & $1(3.33 \%)$ \\
\hline & Sample mean age at examination time & $70.50 \pm \mathrm{SD} 9.62 ; \min 45.50 \max 85.83$ \\
\hline & Males & $71.69 \pm \mathrm{SD} 9.11 ; \min 53.17 \max 82.67$ \\
\hline & Females & $69.71 \pm \mathrm{SD} 10.13 ; \min 45.50 \max 85.83$ \\
\hline & Sample mean age at diagnosis of primary disease & $63.07 \pm \mathrm{SD} 10.89 ; \min 39.00 \max 80.91$ \\
\hline & Males & $64.93 \pm \mathrm{SD} 9.34 ; \min 48.00 \max 80.33$ \\
\hline & Females & $61.81 \pm S D 11.91 ; \min 39.00 \max 80.91$ \\
\hline & Sample mean age on starting BPs & $65.48 \pm \mathrm{SD} 9.34 ; \min 41.50 \max 81.33$ \\
\hline \multirow{9}{*}{ Age } & Males & $67.26 \pm \mathrm{SD} 8.61 ; \min 51.25 \max 75.00$ \\
\hline & Females & $61.30 \pm 9.98 ; \min 41.50 \max 81.33$ \\
\hline & Mean age on starting BPs in M.M. patients & $67.75 \pm \mathrm{SD} 8.04 ; \min 52.00 \max 81.25$ \\
\hline & in MTS of solid cancer patients & $63.67 \pm 10.67 ; \min 41.50 \max 81.33$ \\
\hline & Sample mean age of onset of BRONJ & $67.51 \pm \mathrm{SD} 8.97 ; \min 43.25 \max 82.41$ \\
\hline & Males & $68.12 \pm \mathrm{SD} 8.70 ; \min 51.66 \max 76.91$ \\
\hline & Females & $66.55 \pm$ SDS 9.36; $\min 43.25 \max 82.41$ \\
\hline & Mean age of onset of BRONJ in MM patients & $70.01 \pm \mathrm{SD} 7.61 ; \min 54.58 \max 81.42$ \\
\hline & in MTS of solid cancer patients & $65.32 \pm \mathrm{SD} 10.46 ; \min 43.25 \max 82.41$ \\
\hline
\end{tabular}

Table 2. DRUGS. ZOL: zoledronate; PAM: pamidronate; ALE: alendronate; CLODR: clodronate. Patients MM: multiple myeloma; MTS: metastases of solid cancer; OST: osteoporosis; PO: palate osteosarcoma; CLL: Chronic lymphocytic leukemia; NHL: non-hodgkin lymphoma. ROUTE. IV: intravenous; OS: oral; IM: intramuscolar.

\begin{tabular}{|c|c|c|c|c|c|}
\hline DRUG & \multicolumn{3}{|c|}{ PATIENTS } & ROUTE & ONSET/DOSES \\
\hline $\mathrm{ZOL}$ & $8 \mathrm{MM} 12 \mathrm{MTS} 1 \mathrm{OST}+\mathrm{PO}$ & $2170 \%$ & $258330 \%$ & & $3411 \mathrm{SD}+1215 \mathrm{~min} 8 / \max 61$ everv 28 davs \\
\hline $\mathrm{PAM}+\mathrm{ZOL}$ & 3 MM 1 MTS & $413.30 \%$ & $2583.00 \%$ & & $34.11 \mathrm{SD} \pm 12.15 \mathrm{~min} 8 / \mathrm{max}$ or every 28 days \\
\hline PAM & $1 \mathrm{MM}$ & $13.35 \%$ & & $90 \%$ & \\
\hline $\mathrm{ZOL}+\mathrm{PAM}$ & $1 \mathrm{MTS}$ & $13.35 \%$ & $26.70 \%$ & & $50.50 \mathrm{SD} \pm 19.09 \mathrm{~min} 37 / \mathrm{max} 64$ every 28 days \\
\hline ALE & 1 CLL 1 NHL & $26.70 \%$ & $26.70 \%$ & OS (2) $6.70 \%$ & $146 \mathrm{SD} \pm 161.22 \min 32 / \max 260$ weekly \\
\hline CLODR & $1 \mathrm{OST}$ & $13.30 \%$ & $13.30 \%$ & IM (1) $3.30 \%$ & 500 weekly \\
\hline
\end{tabular}

Tomography scan (CT) and in 12 cases the image showed clear signs of ONJ; ten patients $(33.33 \%)$ had Nuclear Magnetic Resonance Imaging (MRI) and in 9 cases the image showed clear signs of ONJ (Table 6). Statistical analysis of these data (Fisher exact test) showed that the panoramic radiograph does not provide useful information for diagnosis of BRONJ ( $p \leq 0.04)$ and that stage 1 lesions have less probability of being identified than stage 2 or 3 lesions $(\mathrm{OR}=6.1875,95 \%$ CI 1.33 - 28.67) (Figure 1). Conversely, NMR and CT imaging offer a range of findings, depending on the stage and extension of lesions, confirming that these examinations are more reliable for diagnosing osteonecrotic lesions. Used in combination with clinical findings, these imagines improve treatment planning [39-42]. Only 2 patients with ONJ $(6.70 \%)$ in our series had been sub- 
Table 3. Data from oral examination.

\begin{tabular}{|c|c|c|}
\hline SAMPLE & $\mathrm{N}$ & SEX \\
\hline \multirow{2}{*}{ Dentate patients } & \multirow{2}{*}{$25 / 30$} & $\mathrm{M}=11$ \\
\hline & & $\mathrm{F}=14$ \\
\hline \multirow[b]{2}{*}{ Edentulous patients } & \multirow[b]{2}{*}{$5 / 30$} & $M=1$ \\
\hline & & $\mathrm{F}=4$ \\
\hline \multirow{2}{*}{ Mean teeth present } & \multirow{2}{*}{$15.16 \pm 7.70$} & $M=17.10 \pm 6.99$ \\
\hline & & $\mathrm{F}=13.64 \pm 8.13$ \\
\hline \multirow{2}{*}{ Mean teeth decayed } & \multirow{2}{*}{$1.48 \pm 2.46$} & $\mathrm{M}=1.27 \pm 2.83$ \\
\hline & & $F=1.64 \pm 2.27$ \\
\hline \multirow{2}{*}{ Mean teeth filled } & \multirow{2}{*}{$2.24 \pm 2.77$} & $\mathrm{M}=2.82 \pm 3.43$ \\
\hline & & $\mathrm{F}=1.79 \pm 2.15$ \\
\hline \multirow{2}{*}{ Mean remaining roots } & \multirow{2}{*}{$0.56 \pm 1.16$} & $\mathrm{M}=0.45 \pm 1.21$ \\
\hline & & $F=0.64 \pm 1.15$ \\
\hline \multirow{2}{*}{$\begin{array}{l}\text { Patients with } \\
\text { prosthesis }\end{array}$} & \multirow{2}{*}{$17 / 30$} & Fixed $=16$ \\
\hline & & Removable $=17$ \\
\hline \multirow{2}{*}{ Patients with implants } & \multirow{2}{*}{$1 / 30$} & $\mathrm{M}=1$ \\
\hline & & $\mathrm{F}=0$ \\
\hline \multirow{2}{*}{ P.I. } & \multirow{2}{*}{$2.00 \pm 1.01$} & $\mathrm{M}=2.09 \pm 0.85$ \\
\hline & & $\mathrm{F}=1.94 \pm 1.13$ \\
\hline \multirow{2}{*}{ G.I. } & \multirow{2}{*}{$1.85 \pm 0.93$} & $\mathrm{M}=2.02 \pm 0.82$ \\
\hline & & $\mathrm{F}=1.74 \pm 1.00$ \\
\hline $\mathrm{BRONJ} \mathrm{n}=47$ & $\begin{aligned} & \text { Stage } 1 \\
\mathrm{n}= & 20(42.55 \%) \\
& \text { Stage } 2 \\
\mathrm{n}= & 14(29.80 \%) \\
& \text { Stage } 3 \\
\mathrm{n}= & 13(27.65 \%)\end{aligned}$ & $\begin{array}{c}5 \text { Maxilla } \\
15 \text { Mandible } \\
6 \text { Maxilla } \\
8 \text { Mandible } \\
5 \text { Maxilla } \\
8 \text { Mandible }\end{array}$ \\
\hline
\end{tabular}

jected to a dental care protocol aimed at preventing osteonecrosis before start of BP treatment. Seven patients in the series were treated with topical maintenance therapy only, 13 with topical and systemic pharmacological treatment to palliate symptoms associated with systemic infection of the tissues surrounding the area of osteonecrosis; 5 with topical, pharmacological and surgical revision of the lesions under local anesthesia; 5 with topical, pharmacological, surgical revision under local anesthesia and surgical resection under general anesthesia. The outcome at six months was favorable in 6 cases, with complete repair of the tissues overlying the osteonecrotic lesion ( 3 treated with topical, pharmacological, and surgical revision of the lesion under local anesthesia; 3 also with surgery under general anesthesia); in 16 patients the lesion was unchanged (5 treated with topical therapy only; 11 with topical and systemic pharmacological treatment); in 4 patients the lesion deteriorated ( 2 treated with outpatient surgery; 2 with resection under general anesthesia) and 4 died before evaluation ( 2 treated with
Table 4. Number and stage of lesions in the different quadrants (Q1 upper right, Q2 upper left, Q3 lower left, Q4 lower right) of the maxilla and mandible.

\begin{tabular}{|c|c|c|c|}
\hline \multirow{4}{*}{$\begin{array}{c}\text { MAXILLA } \\
17 \text { lesions (36.15\%) }\end{array}$} & \multicolumn{3}{|c|}{$Q 1=$ n $8(17 \%)$} \\
\hline & 1 & 4 & 3 \\
\hline & \multicolumn{3}{|c|}{$\mathrm{Q} 2=$ n $9(19.15 \%)$} \\
\hline & 5 & 2 & 2 \\
\hline \multicolumn{4}{|c|}{$13(27.70 \%)$} \\
\hline MANDIBLE & 7 & 3 & 3 \\
\hline 30 lesions $(63.85 \%)$ & \multicolumn{3}{|c|}{$17(36.15 \%)$} \\
\hline & 9 & 4 & 4 \\
\hline Stage & $1=22$ & $2=13$ & $3=12$ \\
\hline
\end{tabular}

Table 5. Trigger of BRONJ in the patients of our sample afflicted by: MM, multiple mieloma; MTS, metastases of solid cancer; CLL, Chronic lymphocytic leukemia; OST, osteoporosis; NHL, non Hodgkin's lymphoma; OST/PO, osteoporosis and osteosarcoma of palate.

\begin{tabular}{|c|c|c|c|c|c|c|c|}
\hline CAUSES OF BRONJ & $\mathrm{n}$ & $\mathrm{MM}$ & MTs & CLI & OST & NHL & $\mathrm{OST} / \mathrm{PO}$ \\
\hline EXTRACTIONS & $\begin{array}{c}31 \\
66 \%\end{array}$ & 14 & 14 & 0 & 2 & 0 & 1 \\
\hline UNKNOWN & $\begin{array}{c}8 \\
17 \%\end{array}$ & 4 & 4 & 0 & 0 & 0 & 0 \\
\hline $\begin{array}{l}\text { PERIODONTAL } \\
\text { DISEASE }\end{array}$ & $\begin{array}{c}4 \\
8.50 \%\end{array}$ & 1 & 1 & 2 & 0 & 0 & 0 \\
\hline $\begin{array}{l}\text { INCONGRUOUS } \\
\text { PROSTHESIS }\end{array}$ & $\begin{array}{c}3 \\
6.40 \%\end{array}$ & 1 & 0 & 1 & 0 & 1 & 0 \\
\hline PERIMPLANTITIS & $\begin{array}{c}1 \\
2.10 \%\end{array}$ & 0 & 1 & 0 & 0 & 0 & 0 \\
\hline
\end{tabular}

Table 6. Total number of patients examinated; POS: positive report; NEG: negative report; OPT: Panoramic radiography; CT: Computerized axial tomography; MRI: nuclear magnetic resonance imaging.

\begin{tabular}{cccc}
\hline IMAGING & TOTAL & POS & NEG \\
\hline OPT & $30(100 \%)$ & $8(26.70 \%)$ & $22(73.30 \%)$ \\
CT & $13(43.30 \%)$ & $12(92.30 \%)$ & $1(7.70 \%)$ \\
MRI & $10(33.35 \%)$ & $9(90 \%)$ & $1(10 \%)$ \\
\hline
\end{tabular}

topical therapy alone; 2 treated with topical and systemic pharmacological treatment).

\section{DISCUSSION}

The link between the intake of BPs and osteonecrosis of the jaws emerged when reports appeared of these lesions in numerous patients receiving these drugs. Today, the body of evidence is sufficient to support a cause/effect relationship between BP exposure and osteonecrotic lesions [14-24,26,28,30,31,37,41-48]. The incidence of BRONJ varies in different settings, and several other 


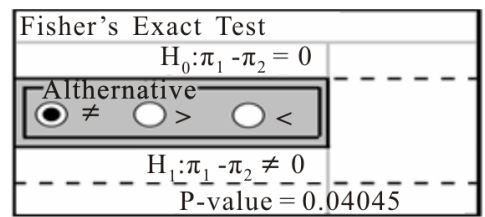

Figure 1. Fisher exact test on significance of panoramic radiograph (OPT) in diagnosing of BRONJ.

risks factors have been indicated that might play a contributory role to the development of BRONJ: the local ones are consistent in literature, whereas the systemic ones (corticosteroids, diabetes, smoking, female gender) are controversial [14-17,20,23,25-28,30,32,37,43-48]. The type of amino-bisphosphonate (pamidronate disodium and zoledronic acid, which are commonly used to treat cancer patients), long-term therapy (high doses), and the intravenous administration route have been indicated as the principal risk factors in inducing BRONJ [14-26,43-49]. Few cases have been reported in patients treated with clodronate [29]. The first AAOMS Position Paper on Bisphosphonate-Related Osteonecrosis of the Jaws [14] subdivided BRONJ into three stages. A stage 0 was added in a second revision [49], to include patients with no clinical evidence of necrotic bone, who present with non-specific symptoms or clinical and radiographic findings. The non-specific findings, which characterize stage 0 , may occur in patients with temporary and definitive absence of bone exposure, but also in patients with a prior history of stage 1, 2, or 3 diseases who have healed and have no clinical evidence of exposed bone [49-51]. Treatment strategies are controversial and depend on the stage of lesions and on Performance Status of the patients [14-16,26,28,39-43,45]. Patients who are only at risk of developing BRONJ because they have been exposed to a bisphosphonate should be informed, and achievement and/or maintenance of optimal periodontal and dental health is mandatory to prevent local risk factors inducing harm and exposure of the alveolar bone. Non-restorable teeth may be treated by removal of the crown and endodontic treatment of the remaining roots. Patients at stage 0 require symptomatic treatment, administration of medication for chronic pain, and control of infection with antibiotics, when indicated. Patients at stage 1 benefit from the use of oral antimicrobial rinses, such as chlorhexidine $0.12 \%$. Patients at stage 2 benefit from the use of oral antimicrobial rinses in combination with antibiotic therapy. Patients at stage 3 benefit from debridement and in some cases bone resection, in combination with antibiotic therapy, which may offer long-term palliation with resolution of acute infection and pain [14-16,25,26,28,37,39-43,45,52-54]. Our study confirms that the panoramic radiograph underestimates the injury and the need to refer all patients with sus- pected bisphosphonate related osteonecrotic lesions on $\mathrm{CT}$ and MRI.

\section{CONCLUSION}

Bisphosphonate-related osteonecrosis of the jaws is a clinical and pathological entity that is not yet fully understood; the true incidence of this adverse effect is almost certainly underestimated. Many patients of our sample were sent from different Institution. For this reason it was not possible to subject all to the same imaging investigations and moreover, even to an untrained eye, evaluative discrepancies appear clearly between different radiologists. The most interesting findings of the current study are the lack of correlation between panoramic radiograph and osteonecrotic lesions, and the high grade of the plaque index and gingival index in patients of this series in spite of recommendations of maintaining a good oral hygiene to prevent oral diseases in patients at risk of BRONJ. In the expectation of results from research that may enable us to prevent osteonecrotic lesions, many works remain to be achieved to improve the education to oral health of physicians, dentists, dental hygienists and patients.

\section{ACKNOWLEDGEMENTS}

The authors thank Mrs. Frances Cooper for linguistic revision of the article and Mr. Matteo Fanuli for the help in the layout of the text.

\section{REFERENCES}

[1] Rodan, G.A. and Fleisch, H.A. (1996) Bisphosphonates: Mechanism of action. Journal of Clinical Investigation, 97, 2692-2696. doi:10.1172/JCI118722

[2] Russel, R.G. and Rogers, M.J. (1999) Bisphosphonates: From the laboratory to the clinic and back again. Bone, 25, 97-106. doi:10.1016/S8756-3282(99)00116-7

[3] Corrado, A. and Cantatore, F.P. (2005) The bisphosphonates: Chemical characteristics, skeletal biological effects and extra-skeletal effects. Reumatismo, 57, 142-153.

[4] Berenson, J.R., Hillner, B.E., Kyle, R.A., Anderson, K. Lipton, A. Yee, G.C. and Biermann J.S. (2002) American Society of Clinical Oncology clinical practice guidelines: The role of bisphosphonates in multiple myeloma. Bisphosphonates Expert Panel. Journal of Clinical Oncology, 20, 3719-3736. doi:10.1200/JCO.2002.06.037

[5] Wu, S., Dahut, W.L. and Gulley, J.L. (2007) The use of bisphosphonates in cancer patients. Acta Oncologica, 46, 581-591. doi:10.1080/02841860701233435

[6] Delmas, P.D. and Meunier, P.J. (1997) The management of Paget's disease of bone. New England Journal of Medicine, 336, 558-566.

doi:10.1056/NEJM199702203360807

[7] Watts, N.B. (2003) Bisphosphonate treatment of osteoporosis. Clinics in Geriatrics Medicine, 19, 395-414. 


\section{doi:10.1016/S0749-0690(02)00069-1}

[8] Hillner, B.E., Ingle, J.N., Chlebowski, R.T., Gralow, J. Yee, G.C., Janjan, N.A., Cauley, J.A., Blumenstein, B.A., Albain, K.S., Lipton, A. and Brown, S. (2003) American Society of Clinical Oncology 2003 update on the role of bisphosphonates and bone health issues in women with breast cancer. Journal of Clinical Oncology, 21, 40424057. doi:10.1200/JCO.2003.08.017

[9] Aapro, M., Abrahamsson, P.A., Body, J.J., Coleman, R.E., Colomer, R., Costa, L., Crinò, L., Dirix, L., Gnant, M., Gralow, J., Hadji, P., Hortobagyi, G.N., Jonat, W., Lipton, A., Monnier, A., Paterson, A.H., Rizzoli, R., Saad, F. and Thürlimann, B. (2008) Guidance on the use of bisphosphonates in solid tumours: recommendations of an international expert panel. Annals of Oncology, 19, 420-432. doi:10.1093/annonc/mdm442

[10] Landesberg, R., Eisig, S, Fennoy, I. and Siris, E. (2009) Alternative indications for bisphosphonate therapy. Journal of Oral and Maxillofacial Surgery, 67, 27-34. doi:10.1016/j.joms.2008.12.006

[11] Mehrotra, B. (2009) Bisphosphonates-Role in cancer therapies. Journal of Oral and Maxillofacial Surgery, 67, 19-26. doi:10.1016/i.joms.2009.01.012

[12] Marx, R.E. (2003) Pamidronate (Aredia) and zoledronate (Zometa) induced avascolar necrosis of the jaws: A growing epidemic. Journal of Oral and Maxillofacial Surgery, 61, 1115-1117. doi:10.1016/S0278-2391(03)00720-1

[13] Migliorati, C.A. (2003) Bisphosphonates and oral cavity avascular bone necrosis. Journal of Clinical Oncology, 21, 4253-4254. doi:10.1200/JCO.2003.99.132

[14] American Association of Oral and Maxillofacial Surgeons (2006) Position paper on bisphosphonate-related osteonecrosis of the Jaws. 1-17.

[15] Ruggiero, S.L., Dodson, T.B., Assael, L.A., Landesberg, R., Marx, R.E. and Mehrotra, B. (2009) American Association of Oral and Maxillofacial Surgeons position paper on bisphosphonate-related osteonecrosis of the jaws 2009 update. Journal of Oral and Maxillofacial Surgery, 67, 2-12. doi:10.1016/j.joms.2009.01.009

[16] Ruggiero, S.L., Mehrotra, B., Rosenberg, T.J. and Engroff, S.L. (2004) Osteonecrosis of the jaws associated with the use of bisphosphonates: A review of 63 cases. Journal of Oral and Maxillofacial Surgery, 62, 527-534. doi:10.1016/j.joms.2004.02.004

[17] Bamias, A., Kastritis, E., Bamias, C., Melakopoulos, I., Bozas, G., Koutsoukou, V., Gika, D., Anagnostopoulos, A., Papadimitriou, C., Terpos, E. and Dimopoulos, M.A. (2005) Osteonecrosis of the jaw in cancer after treatment with bisphosphonates: Incidence and risk factors. Journal of Clinical Oncology, 23, 8580-8587. doi:10.1200/JCO.2005.02.8670

[18] Durie, B.G., Katz, M. and Crowley, J. (2005) Osteonecrosis of the jaw and bisphosphonates. New England Journal of Medicine, 353, 99-102. doi:10.1056/NEJM200507073530120

[19] Migliorati, C.A., Schubert, M.M., Peterson, D.E. and Seneda, L.M. (2005) Bisphosphonate-associated osteonecrosis of mandibular and maxillary bone: An emerging oral complication of supportive cancer therapy. Cancer,

\section{4, 83-93. doi:10.1002/cncr.21130}

[20] Dimopoulos, M.A., Kastritis, E., Anagnostopoulos, A., Melakopoulos, I., Gika, D., Moulopoulos, L.A., Bamia, C., Terpos, E., Tsionos, K. and Bamias, A. (2006) Osteonecrosis of the jaw in patients with multiple myeloma treated with bisphosphonates: Evidence of increased risk after treatment with zoledronic acid. Haematologica, 91, 968-971.

[21] Diel, I.J., Bergner, R. and Grotz, K.A. (2007) Adverse effects of bisphosphonates: Current issues. Journal of Supportive Oncology, 5, 475-482.

[22] Wang, E.P., Kaban, L.B., Strewler, G.J., Raje, N. and Troulis, M.J. (2007) Incidence of osteonecrosis of the jaw in patients with multiple myeloma and breast or prostate cancer on intravenous bisphosphonate therapy. Journal of Oral and Maxillofacial Surgery, 65, 1328-1331. doi:10.1016/j.joms.2007.03.006

[23] Wessel, J.H., Dodson, T.B. and Zavras, A. (2008) Zoledronate, smoking, and obesity are strong risk factor for osteonecrosis of the jaw: A case-control study. Journal of Oral and Maxillofacial Surgery, 66, 625-631. doi:10.1016/j.joms.2007.11.032

[24] Dodson, T.B. (2009) Intravenous bisphosphonates therapy and bisphosphonate-related osteonecrosis of the jaws. Journal of Oral and Maxillofacial Surgery, 67, 44-52. doi:10.1016/j.joms.2008.12.004

[25] Hoff, A.O., Toth, B., Hu, M., Hortobagyi, G.N. and Gagel, R.F. (2011) Epidemiology and risk factors for osteonecrosis of the jaw in cancer patients. Annals of New York Academy of Sciences, 1218, 47-54. doi:10.1111/j.1749-6632.2010.05771.x

[26] Campisi, G., Lo Russo, L., Agrillo, A., Vescovi, P., Fusco, V. and Bedogni, A. (2011) A BRONJ expert panel recommendation of the Italian Society for Maxillofacial Surgery (SICMF) and Oral Pathology and Medicine (SIPMO) on bisphosphonate-related osteonecrosis of the jaws: Risk assessment, preventive strategies and dental management. Italian Journal of Maxillofacial Surgery, 22, 103-124.

[27] Khosla, S., Burr, D., Cauley, J., Dempster, D.W., Ebeling, P.R., Felsenberg, D., Gagel, R.F., Gilsanz, V., Guise, T., Koka, S., McCauley, L.K., McGowan, J., McKee, M.D., Mohla, S., Pendrys, D.G., Raisz, L.G., Ruggiero, S.L., Shafer, D.M., Shum, L., Silverman, S.L., Van Poznak, C.H., Watts, N., Woo, S.B. and Shane, E. (2007) Bisphosphonate-associated osteonecrosis of the jaw: Report of a task force of the American Society for Bone and Mineral Research. Journal of Bone and Mineral Research, 22, 1479-1491. doi:10.1359/jbmr.0707onj

[28] Yarom, N., Yahalom, R., Shoshani, Y., Hamed, W., Regev, E. and Elad, S. (2007) Osteonecrosis of the jaw induced by orally administered bisphosphonates: Incidence, clinical features, predisposing factors and treatment outcome. Osteoporosis International, 18, 1363-1370. doi:10.1007/s00198-007-0384-2

[29] Crépin, S., Laroche, M.L., Sarry, B., and Merle, L. (2010) Osteonecrosis of the jaw induced by clodronate, an alkylbiphosphonate: Case report and literature review. European Journal of Clinical Pharmacology, 66, 547-554. 


\section{doi:10.1007/s00228-010-0822-5}

[30] Lo J.C., O’Ryan, F.S., Gordon, N.P., Yang, J., Hui, R.L., Martin, D., Hutchinson, M., Lathon, P.V., Sanchez, G., Silver, P., Chandra, M., McCloskey, C.A., Staffa, J.A., Willy, M., Selby, J.V. and Go, A.S. (2010) Prevalence of osteonecrosis of the jaw in patients with oral bisphosphonate exposure. Journal of Oral and Maxillofacial Surgery, 68, 243-253. doi:10.1016/j.joms.2009.03.050

[31] Otto, S., Abu-Id, M.H., Fedele, S., Warnke, P.H., Becker, S.T., Kolk, A., Mücke, T., Mast, G., Köhnke, R., Volkmer, E., Haasters, F., Lieger, O., Iizuka, T., Porter, S., Campisi, G., Colella, G., Ploder, O., Neff, A., Wiltfang, J., Ehrenfeld, M., Kreusch, T., Wolff, K.D., Stürzenbaum, S.R., Schieker, M. and Pautke, C. (2011) Osteoporosis and bisphosphonates-related osteonecrosis of the jaw: Not just a sporadic coincidence-A multi-centre study. Journal of Cranio-Maxillo-Facial Surgery, 39, 272-277. doi:10.1016/j.jcms.2010.05.009

[32] Malden, N. and Lopes, V. (2012) An epidemiological study of alendronate-related osteonecrosis of the jaws. A case series from the south-east of Scotland with attention given to case definition and prevalence. Journal of Bone and Mineral Metabolism, 30, 171-182. doi:10.1007/s00774-011-0299-z

[33] Loe, H. and Silness, J. (1963) Periodontal disease in pregnancy. I. Prevalence and severity. Acta Odontologica Scandinavica, 21, 533-551. doi:10.3109/00016356309011240

[34] Silness, J. and Loe, H. (1964) Periodontal disease in pregnancy. II. Correlation between oral hygiene and periodontal correlation. Acta Odontologica Scandinavica, 22, 121-135. doi:10.3109/00016356408993968

[35] Chiandussi, S., Biasotto, M., Dore, F., Cavalli, F., Cova, M.A. and Di Lenarda, R. (2006) Clinical and diagnostic imaging of bisphosphonate-induced osteonecrosis of the jaws. Dento Maxillo Facial Radiology, 35, 236-243. doi: $10.1259 / \mathrm{dmfr} / 27458726$

[36] Arce, K., Assael, L.A., Weissman, J.L. and Markiewicz, M.R. (2009) Imaging findings in bisphosphonate-related osteonecrosis of the jaws. Journal of Oral and Maxillofacial Surgery, 67, 75-84. doi:10.1016/j.joms.2008.12.002

[37] Assael, L.A. (2009) Oral bisphosphonates as a cause of bisphosphonate-related osteonecrosis of the jaws: Clinical findings, assessment of risks, and preventive strategies. Journal of Oral and Maxillofacial Surgery, 67, 35-43. doi:10.1016/j.joms.2009.01.003

[38] Stockmann, P., Hinkmann, F.M., Lell, M.M., Fenner, M., Vairaktaris, E., Neukam, F.W. and Nkenke, E. (2010) Panoramic radiograph, computed tomography or magnetic resonance imaging. Which imaging technique should be preferred in bisphosphonate-associated osteonecrosis of the jaw? A prospective clinical study. Clinical Oral Investigations, 14, 311-317. doi:10.1007/s00784-009-0293-1

[39] Ruggiero, S.L., Fantasia, J. and Carlson, E. (2006) Bisphosphonate-related osteonecrosis of the jaw: Background and guidelines for diagnosis, staging and management. Oral Surgery, Oral Medicine, Oral Pathology, Oral Radiology and Endodontics, 102, 433-441. doi:10.1016/j.tripleo.2006.06.004
[40] Carlson, E.R. and Basile J.D. (2009) The role of surgical resection in the management of bisphosphonate-related osteonecrosis of the jaws. Journal of Oral and Maxillofacial Surgery, 67, 85-95. doi:10.1016/j.joms.2009.01.006

[41] Marx, R.E. (2009) Reconstruction of defects caused by bisphosphonate-induced osteonecrosis of the jaws. Journal of Oral and Maxillofacial Surgery, 67, 107-119. doi:10.1016/j.joms.2008.12.007

[42] Agrillo, A., Filiaci, F., Ramieri, V., Riccardi, E., Quarato, D., Rinna, C., Gennaro, P., Cascino, F., Mitro, V. and Ungari, C. (2012) Bisphosphonate-related osteonecrosis of the jaw (BRONJ): 5 years experience in the treatment of 131 cases with ozone therapy. European Review for Medical and Pharmacological Sciences, 16, 1741-1747.

[43] Woo, S.B., Hellstein, J.W. and Kalmar, J.R. (2006) Narrative review: Bisphosphonates and osteonecrosis of the jaws. Annals of Internal Medicine, 144, 753-761. doi:10.7326/0003-4819-144-10-200605160-00009

[44] Allen, M.R. and Burr, D.B. (2009) The pathogenesis of bisphosphonate-related osteonecrosis of the jaw: So many hypotheses, so few data. Journal of Oral Maxillofacial Surgery, 67, 61-70. doi:10.1016/j.joms.2009.01.007

[45] Thumbigere-Math, V., Sabino, M.C., Gopalakrishnan, R., Huckabay, S., Dudek, A.Z., Basu, S., Hughes, P.J., Michalowicz, B.S., Leach, J.W., Swenson, K.K., Swift, J.Q., Adkinson, C. and Basi, D.L. (2009) Bisphosphonate-related osteonecrosis of the jaw: Clinical features, risk factors, management, and treatment outcomes of 26 patients. Journal of Oral and Maxillofacial Surgery, 67, 1904-1913. doi:10.1016/j.joms.2009.04.051

[46] Vahtsevanos, K., Kyrgidis, A., Verrou, E., Katodritou, E., Triaridis, S., Andreadis, C.G., Boukovinas, I., Koloutsos, G.E., Teleioudis, Z., Kitikidou, K., Paraskevopoulos, P., Zervas, K. and Antoniades, K. (2009) Longitudinal cohort study of risk factors in cancer patients of bisphosphonate-related osteonecrosis of the jaw. Journal of Clinical Oncology, 27, 5356-5362. doi: 10.1200/JCO.2009.21.9584

[47] Barasch, A., Cunha-Cruz, J., Curro, F.A., Hujoel, P., Sung, A.H., Vena, D., Voinea-Griffin, A.E. (CONDOR Collaborative Group) Beadnell, S., Craig, R.G., DeRouen, T., Desaranayake, A., Gilbert, A., Gilbert, G.H., Goldberg, K., Hauley, R., Hashimoto, M., Holmes, J., Latzke, B., Leroux, B., Lindblad, A., Richman, J., Safford, M., Ship, J., Thompson, V.P., Williams, O.D. and Yin, W. (2011) Risk factors for osteonecrosis of the jaws: A case-control study from the CONDOR dental PBRN. Journal of Dental Research, 90, 439-444. doi:10.1177/0022034510397196

[48] Katz, J., Gong, Y., Salmasinia, D., Hou, W., Burkley, B., Ferreira, P., Casanova, O., Langaee, T.Y. and Moreb, J.S. (2011) Genetic polymorphisms and other risk factors associated with bisphosphonate induced osteonecrosis of the jaw. International Journal of Oral and Maxillofacial Surgery, 40, 605-611. doi:10.1016/j.ijom.2011.02.002

[49] Ruggiero, S.L. (2009) Bisphosphonate-related osteonecrosis of the jaw (BRONJ): Initial discovery and subsequent development. Journal of Oral and Maxillofacial 
Surgery, 67, 13-18. doi:10.1016/j.joms.2008.10.005

[50] Colella, G., Campisi, G. and Fusco, V. (2009) American Association of Oral and Maxillofacial Surgeons position paper: Bisphosphonate-related osteonecrosis of the jaws2009 update: The need to refine the BRONJ definition. Journal of Oral and Maxillofacial Surgery, 67, 26982699. doi:10.1016/j.joms.2009.07.097

[51] Bedogni, A., Fusco, V., Agrillo, A. and Campisi, G. (2012) Learning from experience. Proposal of a refined definition and staging system for bisphosphonate-related osteonecrosis of the jaw (BRONJ). Oral Diseases, 18, 621-623. doi:10.1111/j.1601-0825.2012.01903.x

[52] Campisi, G., Di Fede, O., Musciotto, A., Lo Casto, A., Lo Muzio, L., Fulfaro, F., Badalamenti, G., Russo, A. and Gebbia, N. (2007) Bisphosphonate-related osteonecrosis of the jaw (BRONJ): Run dental management design and issues in diagnosis. Annals of Oncology, 18, 168-172. doi:10.1093/annonc/mdm250

[53] Ripamonti, C.I., Maniezzo, M., Campa, T., Fagnoni, E., Brunelli, C., Saibene, G., Bareggi, C., Ascani, L. and Cislaghi, E. (2009) Decrease occurrence of osteonecrosis of the jaw after implementation of dental preventive measures in solid tumour patients with bone metastases treated with bisphosphonates. The experience of the National Cancer Institute of Milan. Annals of Oncology, 20, 137-145. doi:10.1093/annonc/mdn526

[54] Vandone, A.M., Donadio, M., Mozzati M., Ardine, M., Polimeni, M.A., Beatrice, S., Ciuffreda, L. and Scoletta, M. (2011) Impact of dental care in the prevention of bisphosphonate-associated osteonecrosis of the jaw: A single-center clinical experience. Annals of Oncology, 23, 193-200. doi:10.1093/annonc/mdr039 